Revista Herencia, Vol. 31 (2), julio-diciembre, 2018.

\title{
LA FUENTE Y EL GIRASOL: 150 AÑOS DE HISTORIA
}

\author{
The fountain and the sunflower: 150 years of history
}

\author{
José A. Vargas Zamora \\ Universidad de Costa Rica, Costa Rica \\ jose.vargas@ucr.ac.cr
}

Recibido: 04-11-2018

Aprobado: $30-11-2018$

\section{RESUMEN}

José A. Vargas Zamora es profesor Emérito, Escuela de Biología de la Universidad de Costa Rica. Ph.D. en Oceanografía y especialista en ecología de los fondos marinos. $\mathrm{Ha}$ escrito sobre las monedas, medallas, billetes, boletos de café y otros objetos numismáticos.
El 25 de octubre de 1868 fue inaugurada la primera cañería de la ciudad de San José. La tubería culminaba en la Plaza Principal de la ciudad, en donde el agua emanaba de la fuente de Cupido y el Cisne. La fuente, la tubería y la valla para la Plaza fueron importadas desde Inglaterra. En este escrito hacemos uso de imágenes en billetes, monedas y medallas, para ilustrar los eventos relacionados con dicha fuente, especialmente el impacto de la exportación del café a Europa y su influencia en el modo de vida de los ciudadanos de mediados del siglo XIX. La fuente fue el punto de referencia para el pueblo y para los estudiantes de la cercana Universidad de Santo Tomás, fundada en 1844. En 1944 la fuente fue trasladada a la primera sede la Universidad de Costa Rica fundada en 1940. Años después la fuente fue reparada e instalada en el campus central de la Universidad, donde hoy es un símbolo institucional. Este escrito es parte de la celebración del 150 aniversario de la llegada a Costa Rica de Cupido y el Cisne.

Palabras clave: numismática; medallas; billetes; fuentes; Universidad de Costa Rica

\section{ABSTRACT}

On October 25th, 1868, the new water pipe system of the city of San José was inaugurated. The system ended at the central Plaza of the city, where the water emerged from the fountain of Cupid and the Swan. The fountain, the pipe system and the fence for the Plaza were imported from England. In this paper we make use of images in paper money, coins, and medals to illustrate the events related to the fountain, especially the impact of the export of coffee to Europe and its influence on the life habits of the mid XIX century citizens. The fountain was the reference point for people and for the students of the nearby University of Santo Tomas, founded in 1844. In 1944 the fountain was moved to the first location of the University of Costa Rica founded in 1940. Years later the fountain was repaired and moved to the main campus of the University, where today it is an institutional symbol. This paper is part of the celebrations of the $150^{\text {th }}$ anniversary of the arrival to Costa Rica of Cupid and the Swan.

Keywords: numismatics; medals; paper money; fountains; University of Costa Rica 


\section{Introducción}

En la Universidad de Costa Rica, el miércoles 24 de octubre del 2018, a las nueve de la mañana, se dio inicio a la celebración del 150 aniversario de la fuente Cupido y el Cisne, con dos conferencias, una exposición de materiales alusivos a la obra, el develado de una placa, y la degustación de un queque, coronado por una azucarada miniatura de escultura principal de la fuente.

La fuente fue objeto de limpieza y pintura para la celebración, así como mejoramiento del sistema de la bomba y el chorro de agua. La escultura está instalada desde 1992 en la plaza Santo Tomás de la Ciudad Universitaria Rodrigo Facio, San Pedro de Montes de Oca. La Ciudad es la sede central de la Universidad de Costa Rica desde 1957.

La construcción de la cañería en 1868 y el establecimiento de la Universidad de Santo Tomás en 1844, así como las mejoras en la infraestructura y en la vida cotidiana, fueron posibles en parte debido a los recursos económicos generados por la exportación de café y a la adquisición de insumos en Europa. La Universidad, con el girasol como símbolo, y el Parque Central, con la fuente, fueron vecinos cercanos por 75 años y, en cierta forma, de nuevo reunidos, cuando en 1944 la fuente fue colocada en la plaza frente a la nueva Universidad de Costa Rica en barrio González Lahmann. De allí, a fines de la década de 1960 fue trasladada a la Ciudad Universitaria.

Este artículo rememora y a la vez se enmarca --con ayuda de la numismática-- en el contexto de tres efemérides: el 75 aniversario (1940 - 2015) de la fundación de la Universidad de Costa Rica, los 150 años (1868 - 2018) de la inauguración de la fuente de Cupido y el Cisne y los dos siglos desde el nacimiento del Dr. José María Castro Madriz (1818 - 2018), fundador de la República y su primer Presidente, Benemérito de la Patria, rector de Universidad de Santo Tomás y promotor de la fuente.

\section{El acceso al agua en la villita de San José, 1747}

Desde 1564 y hasta 1823 la ciudad de Cartago era la capital del territorio conocido como Costa Rica, que dependía administrativamente de la Capitanía General de Guatemala y esta a su vez del Reino de España. En Costa Rica se estaban 
consolidando nuevos centros de población alrededor de haciendas que producían insumos para consumo local y algunos para exportar, como el tabaco. Con ayuda de los arrieros, los hacendados llevaban, a lomo de mulas, los productos a los territorios vecinos, y ejercían control sobre el trueque de mercancías y el flujo de las escasas monedas coloniales: reales de plata y escudos de oro (Molina-Montes de Oca, 2005, p. 123).

Uno de esos incipientes centros de población, dedicado al patrono San José, carecía de importancia para los potenciales residentes, porque el sitio no estaba cercano a las fuentes de agua. Por ese motivo, el 28 de febrero de 1747 el gobernador de Costa Rica, don Juan Gemmir y Lleonart, emitió un documento en el que se indicaba:

\footnotetext{
"a fin de fomentar la población de la Villa Nueva de la boca del Monte (San José), autorizó al capitán Manuel de Castro - el cual se había comprometido a proveer de agua la población - para que hiciera un repartimiento entre los vecinos con ese objeto. En marzo el capitán Manuel de Castro, que era vecino del valle de Santa Ana, emprendió los trabajos con el auxilio de los vecinos del valle de Aserri" (LeónFernández, 1889, p. 376).
}

En el informe sobre la visita hecha por el obispo Pedro Agustín Morel de Santa Cruz, quien recorrió Costa Rica en 1751, describe el poblado de la Villa Nueva así:

"Cuatro leguas al Norte de Aserrí, en un llano muy ameno, está una población con el diminutivo de Villita, porque ahora se está formando. Compónese de once casas de teja y quince de paja, sin formar plaza ni calle. Faltábale agua y se ha conducido por acequias; la iglesia es la más estrecha, humilde e indecente de cuantas ví en aquella provincia; su titular San José" (León-Fernández, 1889, p. 602).

\section{La capital de Costa Rica a mediados del siglo XIX}

Un siglo después de la visita del obispo Morel la ciudad de San José era la capital de la República de Costa Rica, fundada en 1848. La ciudad crecía rápidamente hacia los cuatro puntos cardinales y ya existía un núcleo central de edificios gubernamentales, una catedral en construcción y una plaza principal, sitio este de reunión de vecinos y visitantes, así como centro de comercio informal los fines de semana. Una cuadra al este de la plaza estaba en construcción el edificio de la Universidad de Santo Tomás, establecida en 1844 y cuyo origen fue la Casa de Enseñanza de Santo Tomás fundada en 1814 (González-Villalobos, 1989, p. 48). 
El edificio fue concluido en 1854, y su aspecto exterior, sobre la avenida segunda, fue grabado en los billetes de 100 colones emitidos por el Banco Nacional de Costa Rica (BNCR) entre 1943 y 1949 (Figura No. 1) Luego las fórmulas sobrantes fueron reselladas y firmadas para circular como billetes del Banco Central de Costa Rica (BCCR) entre 1950 y 1955 (Carranza-Astúa, 2012, p. 360). La emisión de 1943 posiblemente fue para conmemorar el centenario de la Universidad. En el anverso de ese billete aparece grabado el retrato del Dr. Castro Madriz, promotor de la Universidad y quien luego sería rector de la Institución.

Figura N 1. Billete de 100 colones. BNCR 1943-1949 y BCCR 1952-1955. Retrato del Dr. José M. Castro (1818-1892), Fundador de la República y promotor de la Universidad. Edificio de la Universidad de Santo Tomás inaugurado en 1854.
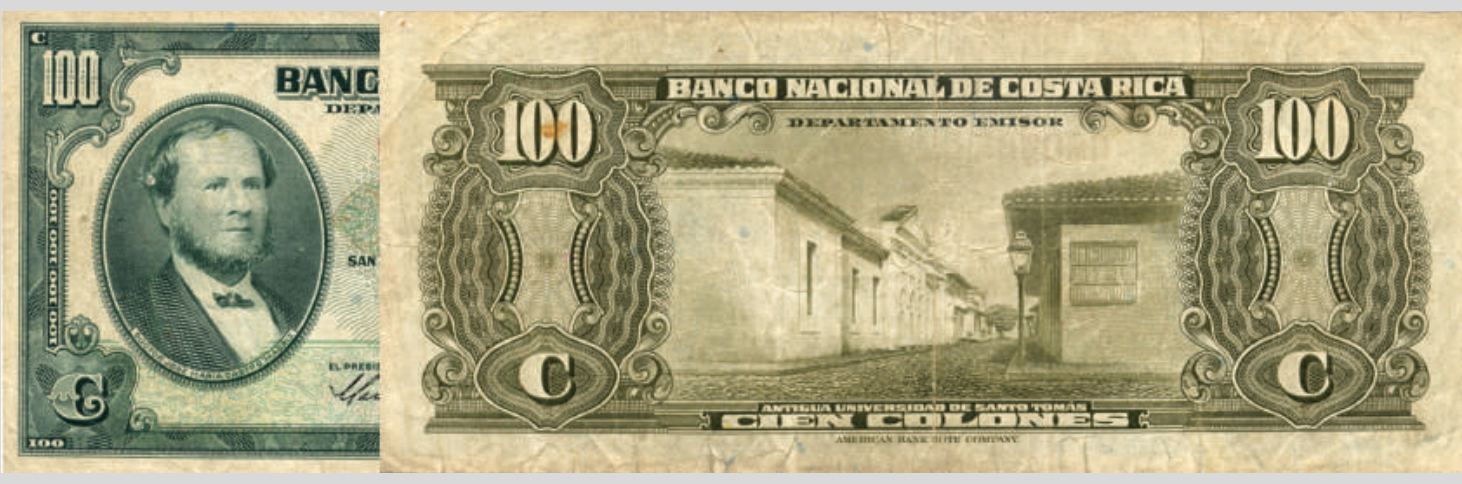

Desde mediados del siglo XIX (1851), se cuenta con un mapa del centro de la ciudad de San José, elaborado por el ingeniero Nicolás Gallegos, en el que aparecen identificados los edificios principales, así como los propietarios de las tierras aledañas. Sin embargo, todavía no existía una cañería, y el agua para las necesidades cotidianas era conducida, al centro de la ciudad, mediante acequias (canales excavados en la tierra) o por taujias (canales revestidos con piedras), ambas expuestos al aire y a la caída de contaminantes en sus cauces (Hilje-Quirós, 2007, p. 78). Dos de esas vías de suministro aparecen, en el mapa, identificadas mediante líneas cortadas: una cruza la calle central una cuadra al norte de la plaza principal y la otra cruza la cuarta avenida desde la cuadra al este de la Universidad (Figura $N^{\circ} 2$ ). 
Figura $\mathbf{N}^{\circ}$ 2. Centro de la ciudad de San José en 1851. Las dos líneas rectas entrecruzadas indican los cuatro puntos cardinales. Las líneas sinuosas cortadas representan las acequias que llevaban el agua al centro de la ciudad. 1. Casa de Joaquín B. Calvo; 2. Cabildo; 3. Universidad de Santo Tomás; 4. Catedral; 5. Casa y tienda de Manuel J. Carazo; 6. Iglesia del Carmen; 7. Casa del Dr. Castro Madriz; 8. Cuartel Principal; 9. Plaza Principal; 10. Casa de Moneda; 11. Almacenes de la República; 12. Corte Suprema; 13. Correos; 14. Casa de Gobierno; 15. Congreso; 16. Casa de Juan Rafael Mora. Modificado de: Herencia, 21(1), p.105. (2008), con base en el plano elaborado por Nicolás Gallegos $(1851,52$ x $66 \mathrm{~cm})$ reproducido por el Instituto Geográfico Nacional.

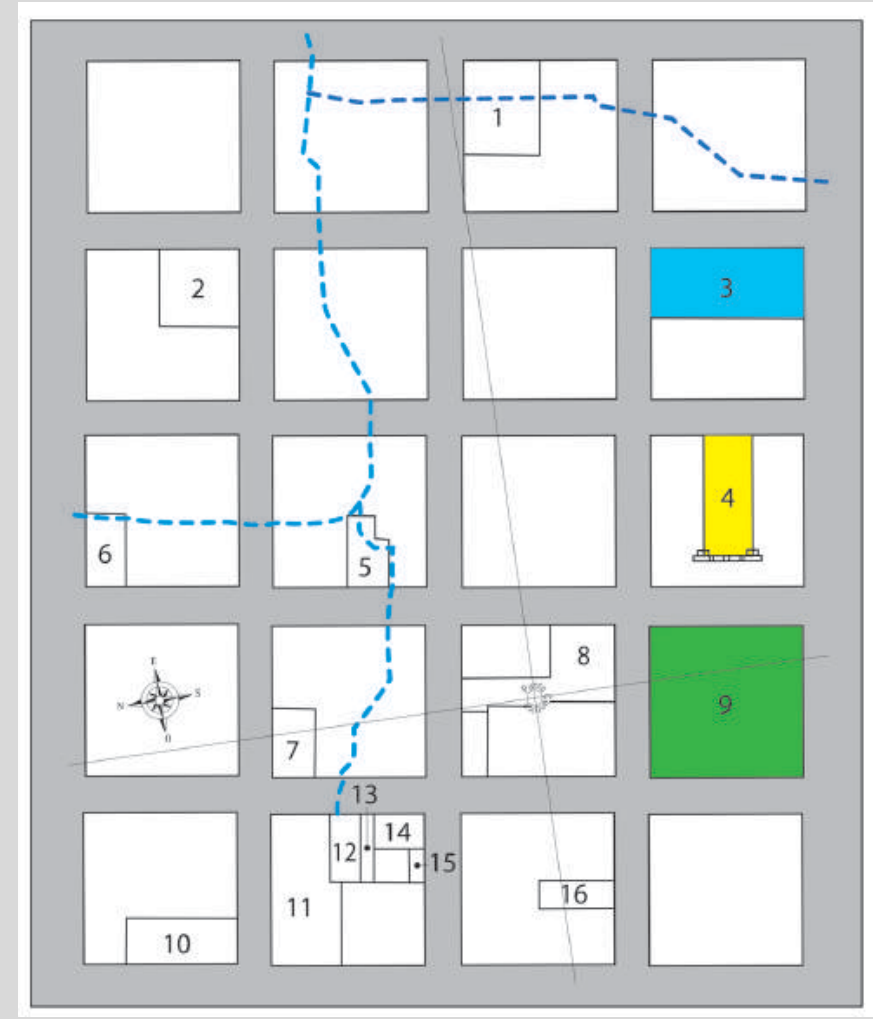

\section{La exportación de café y la influencia europea}

El desarrollo de la ciudad de San José y la introducción de insumos importados principalmente desde Europa, fue posible gracias al auge del cultivo intensivo del café, desde comienzos del siglo XIX. El descubrimiento de las minas de oro en los Montes del Aguacate hizo que muchos mineros invirtieran sus ganancias en plantaciones de café, que comenzaría a ser exportado a Europa, especialmente a Inglaterra (Araya-Pochet, 1973). El transporte de café a Londres fue realizado, casi en su totalidad, por los veleros del capitán William Le Lacheur, quien operó la ruta Puntarenas - Londres - Puntarenas desde 1842 hasta su muerte en 1863. Su compañía naviera continuó con el transporte de café a Londres hasta 1886, con más de una docena de veloces naves (León-Sáenz, 2002, p. 238). 
Uno de esos veleros, de 573 toneladas de desplazamiento y capaz de transportar hasta 13.500 sacos de café, fue bautizado en honor al capitán fundador. El buque aparece grabado en el billete de 10 colones (Figura $N^{\circ} 3$ ) emitido por el Banco Nacional de Costa Rica (BNCR) entre 1942 y 1949 y por el Banco Central de Costa Rica (BCCR) en 1950 (Carranza-Astúa, 2012, p. 357) En el anverso de este billete aparece el retrato de don Manuel José Carazo, Ministro de Hacienda y Guerra, a mediados del siglo XIX.

Los barcos de Le Lacheur zarpaban de Puntarenas cargados de café hacia Londres, en un viaje que demoraba alrededor de 100 días en recorrer los casi $24.000 \mathrm{~km}$ por la peligrosa ruta del Cabo de Hornos. Los buques regresaban de Europa con insumos para vender en Costa Rica, como utensilios metálicos, vajillas de porcelana, telas, ropa hecha, vinos y licores, sardinas enlatadas, quesos de bola, relojes y muebles finos, entre otros (Vega-Jiménez, 1991, p. 56).

La llegada de esos productos favoreció una transición en los hogares costarricenses de los cafetaleros principales, quienes introdujeron objetos importados que contrastaban con los rústicos y escasos elaborados en el país. Por ejemplo, algunos acompañaron o sustituyeron las toscas bancas de fabricación local hechas de tablones cortados con hacha, por sofás importados elaborados con maderas labradas y tapizados con telas finas (Vega-Jiménez, 1991, p. 69) Según lo describe el viajero alemán Wilhelm Marr (Fernández-Guardia, 2002, p. 145), por ahí de 1854 algunos locales comerciales (tiendas) de San José ofrecían una gran variedad de artículos importados a la par de otros productos nacionales. Una de esas estaba localizada en la Calle del Carmen y era atendida (para sorpresa de Marr) en el tiempo libre que le dejaba su alto cargo, por don Manuel J. Carazo. Don Manuel hablaba varios idiomas y tanto él como su contemporáneo, el Dr. Castro Madriz, habían viajado por Europa y conocían de la importancia simbólica que se daba en esas tierras lejanas a algunos objetos, como las fuentes metálicas que emanaban chorros de agua más o menos potable, según los conocimientos de la época. 
Figura $\mathbf{N}^{\circ}$ 3. Billete de 10 colones, BCCR, 1950. Retrato de don Manuel J. Carazo (1808-1877), Ministro de Hacienda y Guerra. Velero clipper William Le Lacheur en Puntarenas.
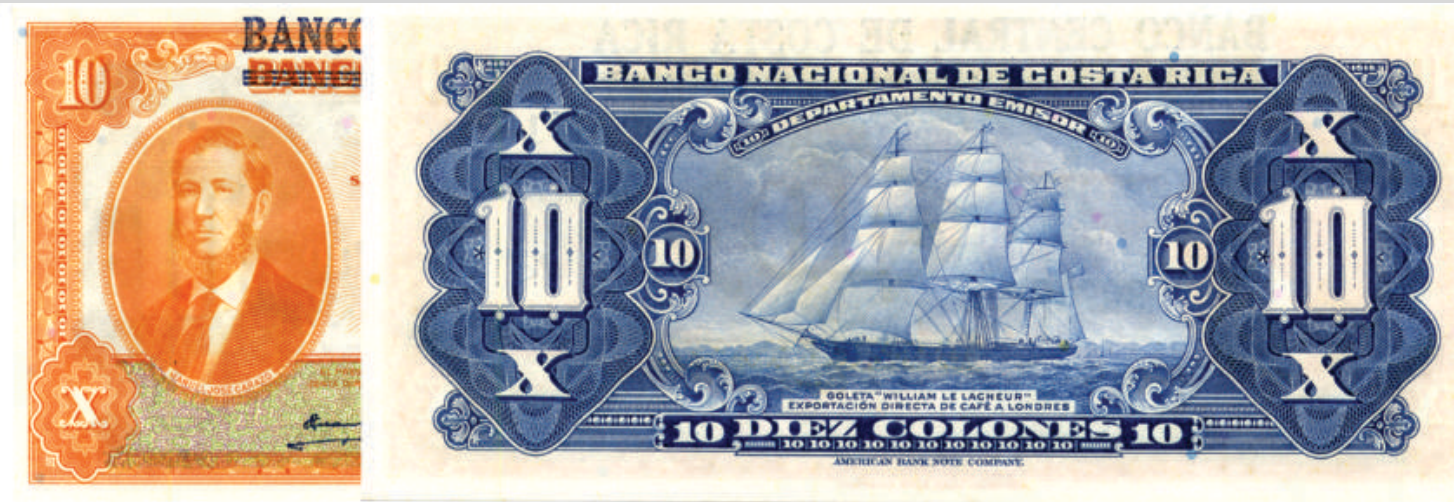

\section{El impacto de la inmigración europea}

En los años siguientes a 1854, Costa Rica continuó con el estímulo de su industria cafetalera, la cual se benefició con la llegada de más inmigrantes de varios países europeos, especialmente de Alemania. El impacto de esta inmigración en el fortalecimiento de los oficios, la agricultura, la agrimensura, las ciencias naturales, las ingenierías y la medicina, es el tema central del libro Trópico Agreste, de HiljeQuirós (2013). Algunos de estos recién llegados se convirtieron, al cabo de los años, en grandes cafetaleros y exportadores de café, maderas, y otros productos nacionales. Menciono aquí a cuatro de ellos, quienes realizaron labores diferentes: el Dr. Wilhelm Witting, fue edecán y traductor del presidente Juan Rafael Mora durante la guerra contra los filibusteros (1856-1857), y luego ejerció los cargos de ensayador y director de la Casa de Moneda. El médico Karl Hoffmann fue el cirujano mayor del ejército costarricense durante la guerra. El naturalista Alexander von Frantzius abrió en 1858 una de las primeras farmacias (boticas) de San José y publicó en 1869 un mapa detallado del territorio de Costa Rica, que incluye un sondeo de las profundidades del puerto de Limón, abierto al comercio en 1867. El ingeniero Ludwig von Chamier, fue el encargado de ampliar el sendero de la ruta del Sarapiquí, para el tránsito de carretas, labor que quedó inconclusa por la falta de maquinaria y la guerra (Vargas-Zamora, 2012, p. 15). 
Esos inmigrantes también enfrentaron un país con condiciones sanitarias muy precarias. El agua contaminada de las acequias facilitaba la dispersión de los parásitos intestinales y de las epidemias, como la del cólera, consecuencia esta última de las batallas de la guerra contra los filibusteros. Pasada la epidemia, fue aún más evidente la necesidad de proveer de cañería a la ciudad capital, por lo que dos de esos inmigrantes alemanes, Franz Kurtze y Wilhelm Nanne formaron una empresa, que el 20 de abril de 1858 publicó el siguiente aviso en la prensa local:

\begin{abstract}
"Los que suscriben, autorizados por contrata celebrada con el Supremo Gobierno para establecer la cañería en ésta Capital y proveer de agua por el término de cinco años las casas particulares, tienen el honor de avisarle al público que los pedidos de estatuas, monumentos, fuentes escogidas de patio o jardín, llaves, waterclosets, regaderas o bombas, etc, etc, y otros objetos necesarios para el abasto de las habitaciones, deben precisamente hacerse en éste año corriente: y por éste motivo suplican a los propietarios de casa, que quieran aprovecharse de ésta oportunidad, se sirvan dirigirse a su oficina hasta el día seis de Mayo entrante, para designar los objetos que desean escoger, entre varios diseños que al efecto se han proyectado" (Hilje-Quirós, 2007, p. 79)
\end{abstract}

Tal como lo hemos mencionado, esos insumos eran en su mayoría importados de Europa, traídos hasta Puntarenas en veleros como los de Le Lacheur, y luego transportados en carretas hasta la capital, previo pago de los impuestos respectivos en la aduana de La Garita (Fernández-Guardia, 2002, p. 125). La importancia de esta ruta, habilitada para carretas desde 1844, fue fundamental en el desarrollo de Costa Rica. Por esta razón, un grabado del puente de La Garita, a mediados del siglo XIX, aparece en el reverso de los billetes de cinco colones emitidos por el BNCR entre 1943 y 1949 y por el BCCR entre 1950 y 1951 (Figura No 4) En el anverso se incluyó el retrato de don Braulio Carrillo Colina, organizador del Estado costarricense y Benemérito de la Patria (Carranza-Astúa, 2012, p. 356) El grabado original del puente de La Garita aparece en Meagher (1860, p. 33), quien hace una extensa descripción de la vida cotidiana y costumbres en la Costa Rica de 1858. Esa publicación incluye otros grabados, como el puerto de Puntarenas, las carretas en el Monte del Aguacate, la Plaza y Catedral de San José y otros edificios de la capital y Cartago. 
Figura $N^{\circ}$ 4. Billete de 5 colones, BNCR, 1943. Retrato de don Braulio Carrillo (1800-1845) Jefe de Estado. Puente de la Garita a mediados del siglo XIX, Patrimonio Nacional y en funcionamiento en la actualidad.
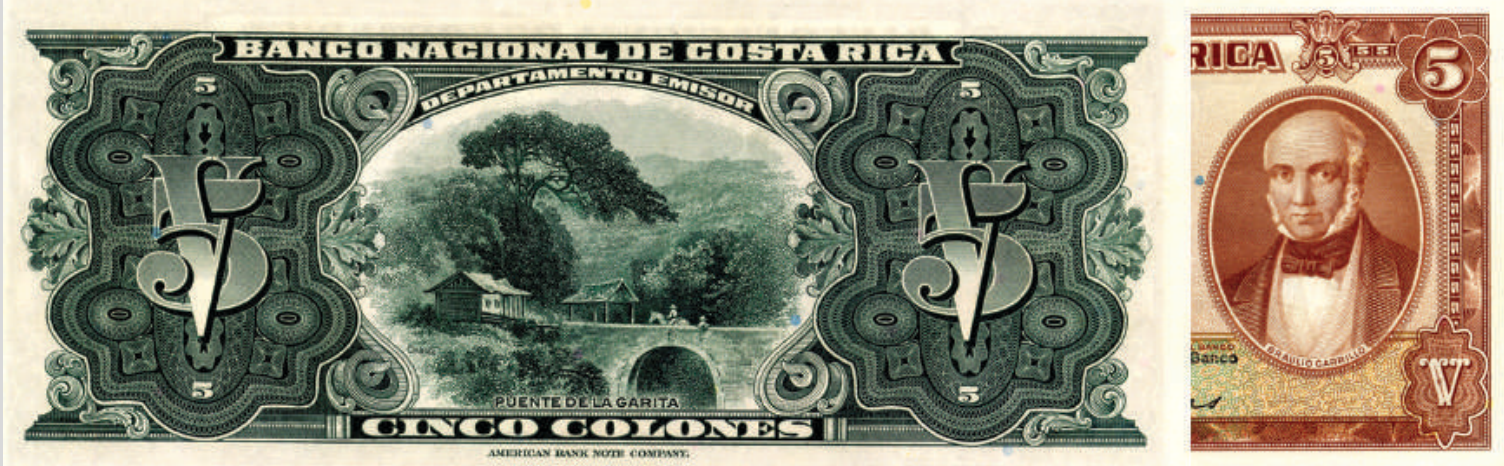

Los gastos de la guerra de 1856-1857 afectaron negativamente el presupuesto nacional, por lo que no fue posible concluir el proyecto de la cañería. No obstante, Kurtze y Nanne ya habían hecho en 1858 una inversión de 43.000 pesos en la compra de tubería, lo que los puso en serios aprietos financieros (Hilje-Quirós, 2007, p. 79). El proyecto fue contratado de nuevo en 1864 a cargo del ingeniero mexicano don Ángel Velásquez, quien lo concluyó en 1869. En 1865 el ingeniero Velásquez asumió la cátedra de ingeniería civil, arquitectura y agrimensura en la Universidad de Santo Tomás, y en 1867 fue el encargado de viajar a Inglaterra y traer los materiales faltantes para la cañería. Don Ángel adquirió, además, la réplica de la fuente de Cupido y el Cisne, la fuente de Moisés para la pared de los tanques de almacenamiento del agua, y la reja perimetral de la manzana del futuro Parque Central de San José. El precio de catálogo de la fuente de Cupido y el Cisne era de 200 libras esterlinas (Orozco, 2016).

\section{Monedas, boletos de café y billetes en 1868}

El pago de las 200 libras esterlinas posiblemente no representó un problema cambiario para don Ángel, pues un decreto del 27 de setiembre de 1848, firmado por el Dr. Castro Madriz, permitía que la moneda inglesa conocida como libra esterlina o soberano de oro circulara en el país por el valor de cinco pesos. Por tal motivo, durante muchos años las monedas de cinco pesos y los billetes de cinco colones, fueron conocidos con el sobrenombre de libras. La tasa de cambio aumentó a 5.45 pesos por decreto de 1871 (Murillo, 2004, págs. 66 y 99). En 
consecuencia, el precio de compra de la fuente de Cupido y el Cisne fue un poco más de 1000 pesos costarricenses.

En 1858, un pantalón de casimir inglés costaba 18 pesos. Sin embargo, el salario mensual de un jornalero apenas rondaba esa suma. Para curarse de las lombrices intestinales, la ictericia, la tisis, el asma y muchas otras enfermedades se podía adquirir la panacea de las píldoras de Holloway, importadas de Inglaterra, y accesibles por un peso la caja de 12 docenas (Vega-Jiménez, 1991, p. 63).

En 1864 Costa Rica adoptó el sistema monetario decimal, por lo que un peso equivalía a 100 centavos (Murillo, 2004, p. 89). Se sustituyó con este sistema al de los reales de plata ( 1 Peso $=8$ reales) y escudos de oro (16 pesos $=1$ Onza $=8$ escudos), en uso desde tiempos coloniales. No obstante ese cambio, el lenguaje de los reales sobrevivió en Costa Rica por más de un siglo y hoy todavía se habla de pesos.

En 1868 circulaban monedas de un cuarto de centavo y de un centavo acuñadas en una aleación de cobre y níquel. También se disponía de monedas de plata con valores de 5, 10, 25 y 50 centavos (Figura No 5).

Las monedas de plata tenían grabado en el reverso, a partir de 1850 y hasta 1875, como símbolo de la fortaleza y hospitalidad de la nueva República, un árbol de encino o roble (del género botánico Quercus), abundantes en la Costa Rica de la época, y también en Europa, (Vargas-Zamora, 2014). La cara principal de las monedas, el anverso, tiene grabado el Escudo de Armas de Costa Rica, que en la moneda de plata aparece con armas, y sin ellas en la de oro. En la base del escudo de la de plata se entrecruzan, una rama similar a la del mirto europeo (Myrtus communis, símbolo de paz) con una palma (posiblemente una hoja de la palmera datilera del Viejo Mundo, Phoenix dactylifera, símbolo de victoria). Las coronas con frutillos pedunculados en el reverso del centavo y la moneda de oro oscilan entre las representaciones del mirto y del laurel europeo (Laurus nobilis, símbolo de nobleza y mérito utilizado por los emperadores romanos y reyes españoles). Dos ramas del mirto aparecen semiocultas en el Escudo Nacional actual (VargasZamora y Gómez-Laurito, 2006).

De vez en cuando se hacía uso de una u otra moneda de oro, cuyos valores eran equivalentes a uno, dos, cinco y 10 pesos (Figura № 5). En las plantaciones de café (cafetales) se utilizaban monedas privadas conocidas como boletos de café 
(Figura $\mathrm{N}^{\circ} 5$ ) para el pago de la recolecta del grano. El administrador del cafetal cambiaba los boletos por dinero, al concluir la cosecha o la semana laboral. También en 1868 circulaban algunos billetes, en denominaciones de 1, 2, 5, 10, 25, 50 y 100 pesos (Carranza-Astúa, 2012, págs. 53 y 99).

Figura $\mathbf{N}^{\circ}$ 5. Monedas oficiales y privada emitidas entre 1864 y 1875: A. Un centavo 1868, cuproníquel. B. Boleto de café, 1867, cupro-níquel; Salvador Jiménez, cinco centavos, con un cafeto. C. 25 centavos (peseta), plata, 1875, con el árbol de encina o roble. D. Cinco pesos 1868, oro.

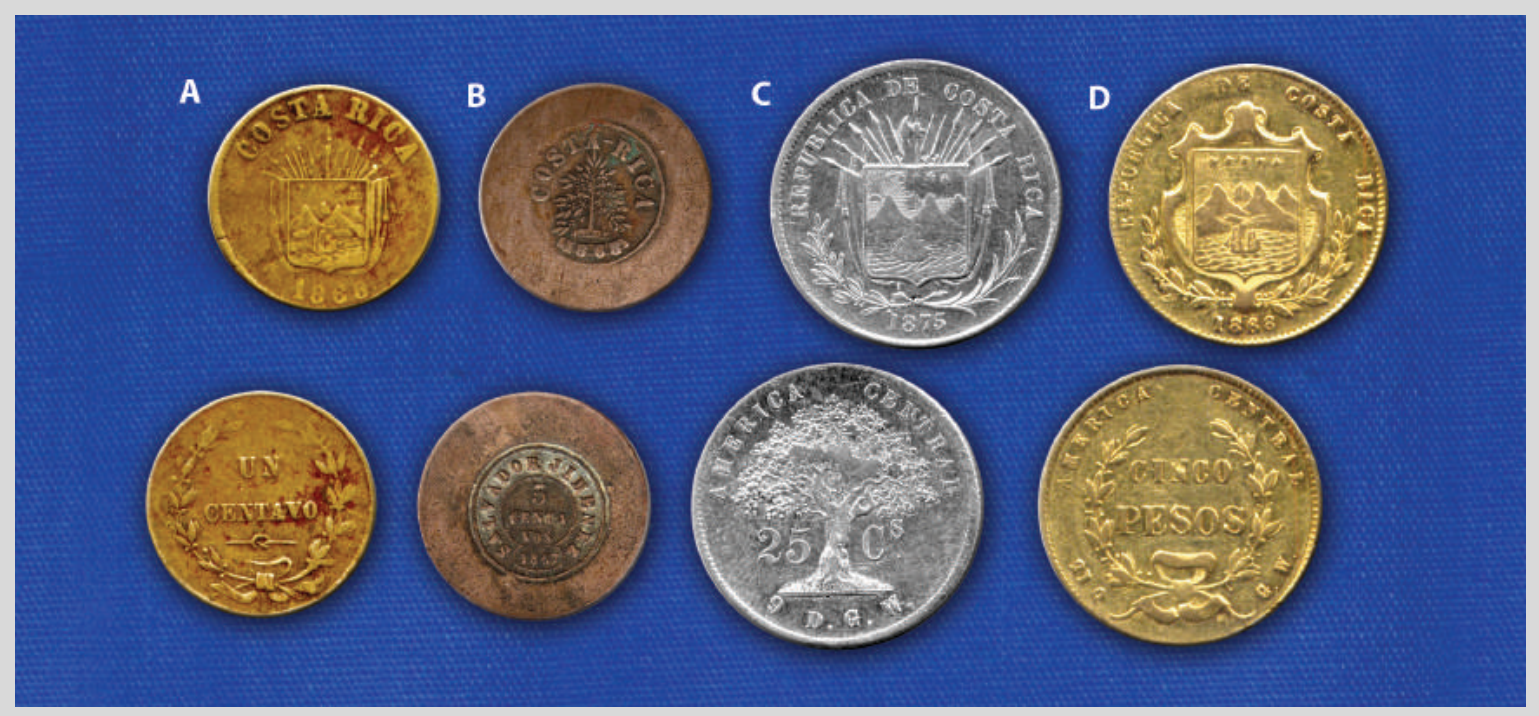

\section{La fuente y la plaza como puntos de reunión}

La inauguración de la primera cañería de San José se realizó el 25 de octubre de 1868 y fue presidida por el Dr. Castro Madriz, quien ejercía nuevamente el cargo de Presidente de la República y por el sacerdote Llorente y Lafuente, primer obispo de Costa Rica. La culminación de la obra, que conducía el agua desde unos tanques ubicados contiguo al actual Hospital Calderón Guardia y que hoy permanecen en pie, era la fuente de Cupido y el Cisne ubicada en la plaza Principal de la capital, al frente de la Catedral. La fuente para la Plaza, la destinada para los tanques, y la reja metálica que rodearía la cuadra de dicha Plaza fueron importadas de Inglaterra a fines de 1867, y transportadas hasta Puntarenas, a bordo del velero William Le Lacheur. Desde el puerto hasta la capital se les transportó, en carretas, por la ruta de los Montes del Aguacate, que pasa por el puente de La Garita (Orozco, 2016). 
La fuente de Cupido y el Cisne sirvió como punto de reunión y referencia por 75 años, tanto para los visitantes de la ciudad, como para los locales que, antes de que la transformación de la plaza en Parque, aprovechaban el mercado improvisado que tenía lugar los sábados.

La Plaza Principal de San José era el centro de comercio sabatino desde tiempos coloniales. El viajero Wilhelm Marr menciona que, en 1854:

"La gran plaza se cubre de barracas cubiertas de lienzo, en las que el pequeño comercio pone también en venta todos los productos de la industria extrajera. En el día de mercado el presidente de la República no desdeña cortar algunas varas de tela para el campesino; el ministro de Hacienda se queda ronco en su afán de probarle al comprador que pierde en la venta de un vaso de vidrio"(Fernández-Guardia, 2002, p. 141).

El escritor Manuel González Zeledón (Magón, 1864-1936) describe su visita a ese mercado improvisado cuando él era un niño, en su cuento Un día de mercado en la Plaza Principal, escrito en 1896:

"Chanita cogía una sombrilla y su pañolón, yo la canasta y los sacos, y ambos emprendíamos la marcha hacia la Plaza Principal, hoy Parque Central...

...La Plaza Principal, con su baranda de hierro, sus hermosos higuerones e higuitos y su pila monumental, únicos testigos mudos de aquellas escenas, era el lugar de mercado a donde acudían los vendedores y compradores, unos en espera de la módica ganancia, los otros en busca del pan nuestro de cada semana" (GonzálezZeledón, 1998, p. 23).

Una vez establecido el parque Central, la fuente fue el punto de encuentro diario de pobres y ricos. Durante el descanso dominical los pudientes y los que aparentaban serlo, ataviados con sus trajes de dominguear, se reunían en el parque a intercambiar noticias, iniciar o concluir amoríos, pactar negocios y escuchar a la banda del cuartel Principal, que al abrigo del antiguo quiosco (Figura № 6) ejecutaba su repertorio después de la misa en la Catedral. El Cuartel estaba localizado en la cuadra al norte del parque. También, para los que podían costearlo, de vez en cuando alguno de los escasos fotógrafos ofrecía sus servicios. 
Figura $N^{\circ}$ 6. El Parque Central de San José a inicios del siglo XX. Foto tomada mirando hacia el oeste. La fuente de Cupido y el Cisne a la izquierda y al fondo, el quiosco para los conciertos. Tarjeta postal coloreada a mano. Fotógrafo: Manuel Gómez Miralles (1886-1965).

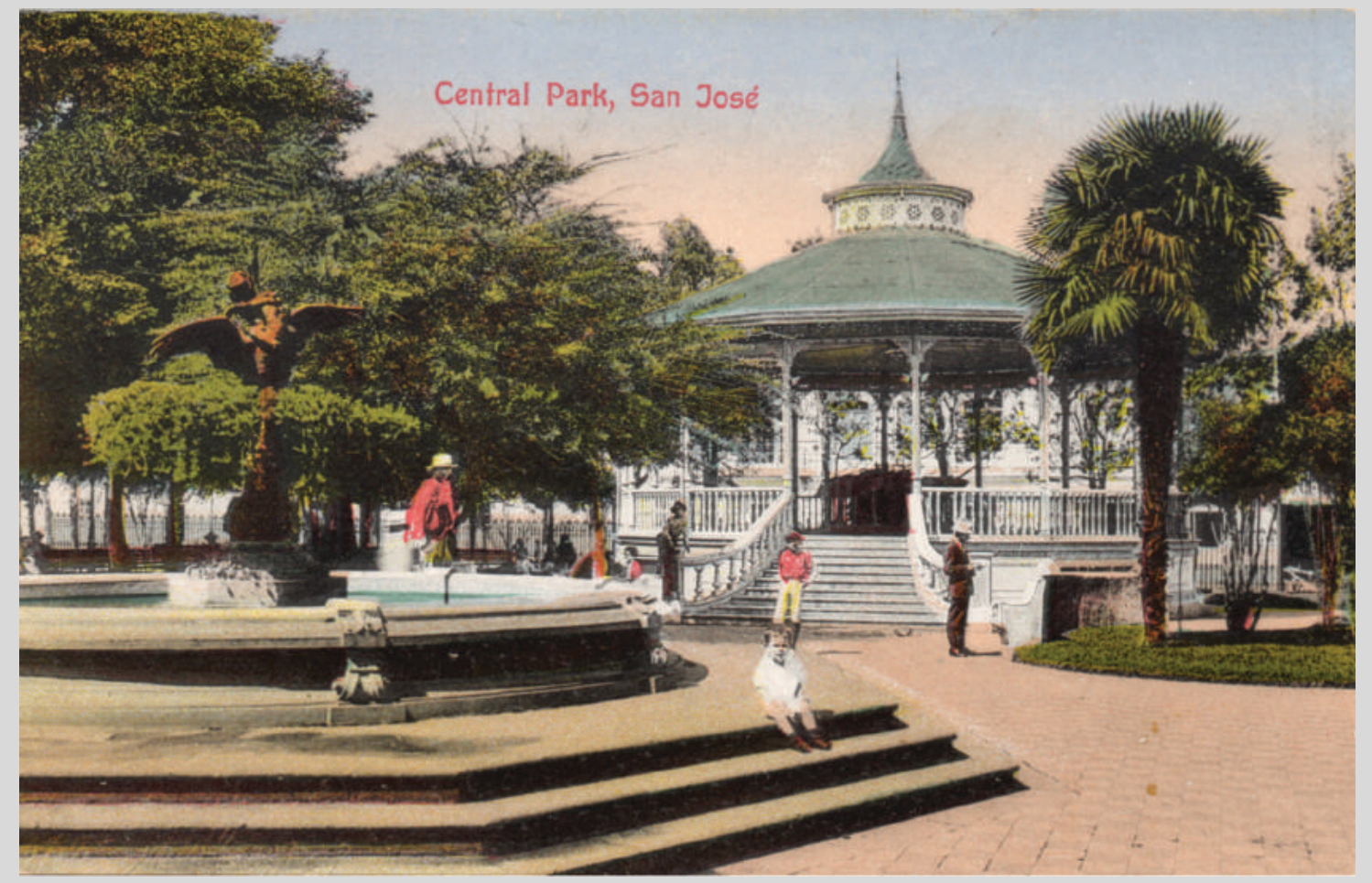

El aspecto que tenía la fuente, con su pila circular, por el año 1870, cuando la plaza estaba por ser transformada en el nuevo parque Central, aparece grabado en los billetes de dos colones emitidos por el BNCR entre 1946 y 1949 y por el BCCR en 1967 (Carranza-Astúa, 2012, p. 350). Esta imagen (Figura No 7) hizo recordar la fuente, entre los costarricenses de mediados del siglo XX, que la conocieron en el parque Central, pues en 1944 fue trasladada a la nueva Universidad de Costa Rica (Orozco, 2016). El billete dio a conocer a la fuente de Costa Rica en todo el mundo, pues los billetes eran y son documentos muy buscados por los coleccionistas.

El anverso de ese billete, de tono rojizo, tiene grabado en retrato de don Joaquín Bernardo Calvo, quien ocupó varios cargos, como el de Ministro de Hacienda y diplomático en varios de los gobiernos de mediados del siglo XIX. 
Figura No 7. Billete de 2 colones, BNCR, 1948. Retrato de don Joaquín B. Calvo (1799-1865), Ministro de Relaciones Exteriores. Fuente de Cupido y el Cisne recién instalada en la Plaza Principal de San José.
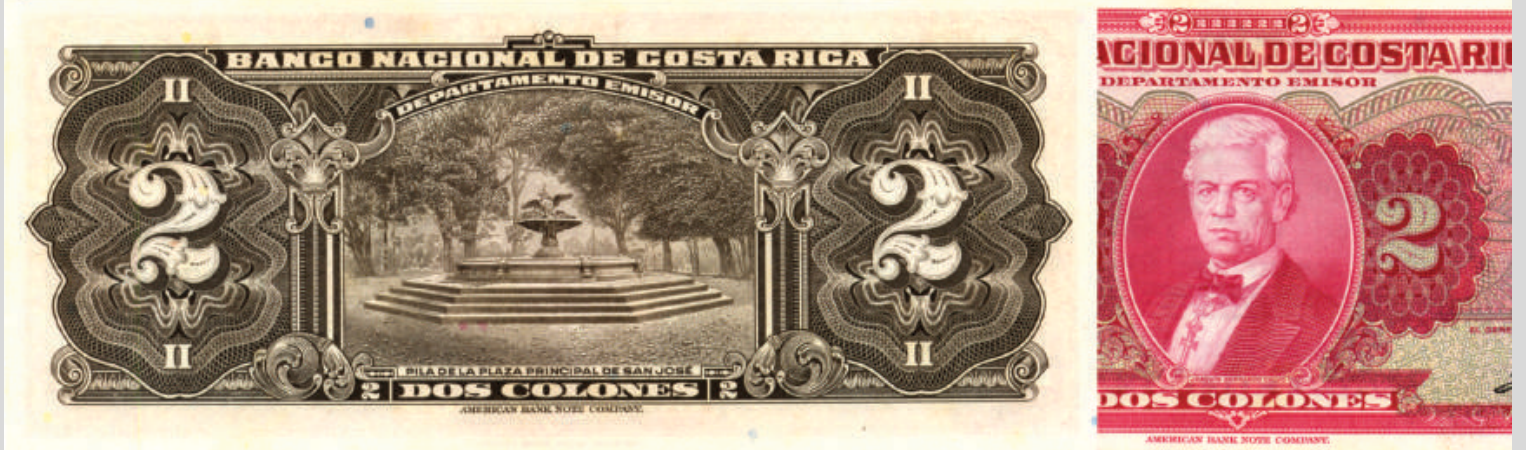

\section{Cupido y el Cisne, la Universidad y el Dr. Castro}

Entre los asiduos visitantes que se sentaban en el octágono, formado por los tres niveles de gradas que servían de base a la pila y fuente de Cupido y el Cisne, posiblemente estaban muchos de los estudiantes y algunos profesores de la Universidad de Santo Tomás, situada una cuadra al este (Figura №2) La Institución se mantuvo funcionando, como tal, hasta 1888 (González-Villalobos, 1989). Precisamente el año anterior (1867) a la inauguración de la fuente, el artista Achiles Bigot hizo un retrato al óleo, de tamaño real, del Dr. Castro Madriz, quien aparece posando su mano derecha sobre el documento de creación de la Universidad de Santo Tomás (Figura No 8). El Dr. Castro luego fue su rector por varios años y durante uno de esos periodos en el ejercicio de la rectoría, en 1878, le correspondió, entregarle su diploma de graduación de enseñanza media a un adolescente de 14 años, quien luego, ya convertido en un escritor, adoptaría el seudónimo de Magón. Así describió el evento en su cuento, Mi primer empleo:

"Los corredores del Instituto Nacional, antigua Universidad de Santo Tomás, apenas si podían contener el numerosísimo concurso que en estrecha apretazón principió a llenarlos desde las once de la mañana...

...colgaban desde el muro los tres retratos característicos..., y el del doctor José María Castro, mostrando un pergamino con la "Ley de erección de la Universidad" con una pluma de ave en la derecha y sus cruces de la Legión de Honor en la solapa del frac...

...solo las primeras filas estaban destinadas a los colegiales que iban a recibir en ese día, solemnemente y de manos del Presidente de la República, unos sus medallas, otros sus objetos de premio, otros sus certificados honoríicos y todos la bendición de la patria y la voz de aliento de sus conciudadanos... 
Revista Herencia, Vol. 31 (2), julio-diciembre, 2018.

...Entró el General Guardia con su brillante uniforme de gala, sombrero elástico coronado de ancha pluma de avestruz, frac azul cubierto de bordados de laurel y encino, pantalón de ante con anchísimo galón, bota de charol hasta la rodilla...

...Le hacía pendant a la izquierda del General, el Doctor don José Maria Castro, Ministro de Instrucción y Rector de la Universidad, luchador constante por la instrucción pública, que era su culto, con frac y pantalón negro, chaleco blanco escotado, sombrero de copa...

...Los alumnos fuimos colocados en las sillas destinadas par el caso al lado derecho de la mesa presidencial. Después de las disertaciones y exposición de las tesis, el Director, en pie, leyó con vos clara los nombres de los discípulos premiados; cada vez que se prendía del pecho una medalla, un murmullo de aprobación se levantaba de aquel millar de cabezas" (González-Zeledón, 1998, p. 41)

\section{Afortunadamente, el retrato del Dr. Castro ha sobrevivido hasta nuestros días, y está custodiado, como tesoro artístico en la actual Universidad de Costa Rica.}

Figura N 8. Retrato al óleo del Dr. José María Castro Madriz, Presidente de la República, realizado por el artista Achilles Bigot en 1867. El retrato está hoy en la Universidad de Costa Rica. Foto: JVZ.

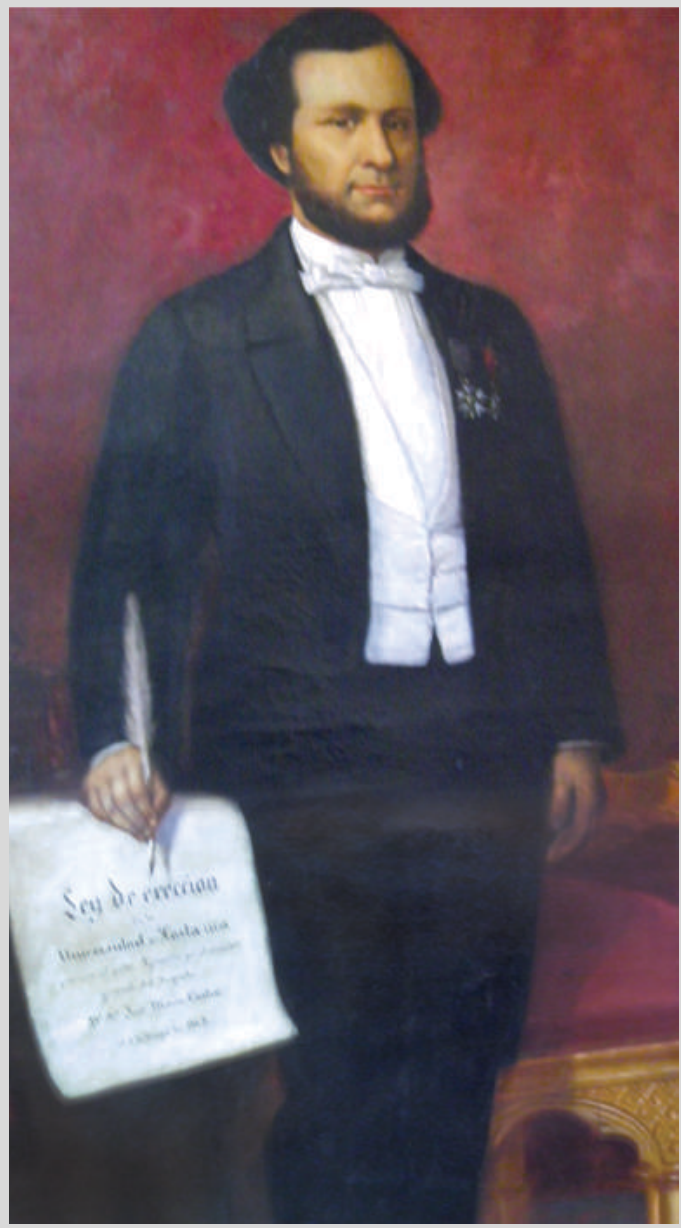




\section{El girasol en las medallas y certificados de la Universidad}

Los diplomas de graduación otorgados por la Universidad de Santo Tomás eran encabezados por el título en latín Divi Thomae Universitas Costarricensis y, al pie, el sello de la institución, con un girasol y la leyenda Universidad de Costa Rica (Hilje-Quirós, 2013, p. 530). Recientemente, aparecieron en una colección privada, dos objetos que menciona Magón en su cuento (Figura No 9): el primero es un ejemplar de las medallas de premiación de los alumnos, y el otro uno de los certificados honoríficos. El ejemplar de la medalla tiene grabado, y el certificado, impreso, el escudo de la Universidad de Santo Tomás, ambos con el girasol (Helianthus annus), planta originaria de América y llevada a Europa. El girasol, cuando joven, orienta sus flores para seguir el movimiento del sol, y por esto se le da el simbolismo de buscar la luz del conocimiento: LUCEM ASPICIO, frase latina que traducida al español, es busco la luz o aspiro la luz. Es interesante que, tanto en los sellos de tinta, como en la medalla se lee UNIVERSIDAD DE COSTA RICA, mientras que en el diploma y en el certificado se lee UNIVERSIDAD DE SANTO TOMAS.

El certificado, otorgado en 1865 al estudiante Manuel Peralta de la carrera de Derecho Público, está suscrito por el Dr. Castro, como rector. Las medallas de plata fueron emitidas entre 1875 y 1883, periodo en el que funcionó, como entidad de enseñanza media, el Instituto Nacional, en el edificio de la Universidad (GonzálezVillalobos, 1989, p. 66).

Estas representaciones del escudo institucional, posiblemente, son las más antiguas conocidas y que, con algunas modificaciones, corresponden al que desde su fundación en 1940 adoptó la Universidad de Costa Rica. 
Figura $\mathbf{N}^{\circ}$ 9. Certificado honorífico, como testimonio de aplicación y progreso, otorgado el 20 de diciembre de 1865 al estudiante Manuel Peralta, alumno de la clase de Derecho Público en la Universidad de Santo Tomás de Costa Rica. El certificado es avalado por el Rector Dr. Castro Madriz. A la izquierda una ampliación del sello incluido en el certificado y en el que aparece el girasol orientado hacia el lector y las leyendas Lucem Aspicio y Universidad de Costa Rica. A la derecha, un ejemplar de la medalla de plata $(41 \times 25 \mathrm{~mm})$ que se otorgaba a estudiantes del Instituto Nacional (1875-1883). El girasol mira hacia el sol naciente. La medalla tiene como corona dos ramas de laurel europeo (Laurus nobilis), con frutillos.

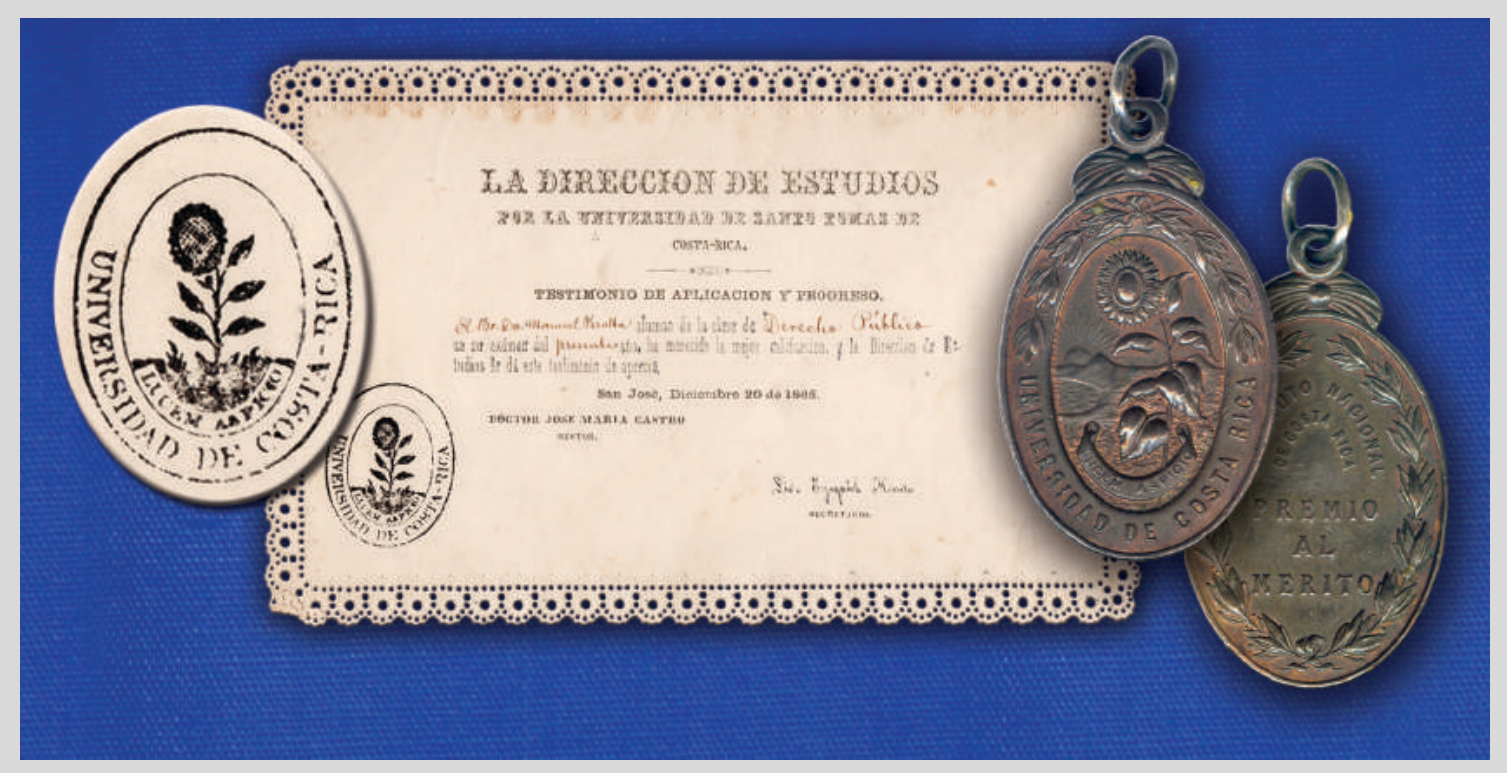

\section{Cupido y el Cisne en la Universidad de Costa Rica}

La fuente de Cupido y el Cisne permaneció instalada en el Parque Central de San José, entre 1868 y 1944, cuando por remodelaciones del Parque, y ante pedido de la Universidad, la Municipalidad acordó donarla a la nueva Universidad de Costa Rica, fundada en 1940, en la administración del Dr. Rafael Angel Calderón Guardia. La imagen de la fuente que se colocó frente al edificio de la Universidad (Figura No 10) fue grabada en el billete de 20 colones, emitidos por el BCCR entre 1952 y 1964 (Carranza-Astúa, 2012, p. 375).

El anverso del billete contiene el retrato del joven Dr. Clodomiro Picado Twight (1887-1944) pionero mundial de la ecología y la microbiología. El Prof. José Joaquín Jiménez Núñez, entonces rector de la Universidad de Costa Rica, expresó en el funeral de don Clorito: 
"La Universidad enluta su estandarte y se prepara para honrar la memoria en Asamblea Solemne, donde haya de analizarse mejor su figura egregia, como que se ha ido a recibir el galardón de los buenos quien fuera su miembro de honor y su benefactor insigne, y será entonces cuando se diga el juicio cabal y la palabra justa sobre este verdadero grande de la ciencia, de la caridad y de la Patria" (PicadoChacón, 1964, p. 281).

En honor del Dr. Picado fue establecido en 1976 el Premio Nacional de Ciencia y Tecnología que lleva su nombre.

La fuente estuvo en ese sitio del barrio González Lahmann, hasta mediados de la década de 1960, cuando se decidió removerla por motivo del traslado de la Universidad a su nueva sede en la Ciudad Universitaria, en San Pedro de Montes de Oca (Orozco, 2016).

Figura No 10. Billete de 20 colones, BCCR, 1960. Retrato del Dr. Clodomiro Picado Twight. Biólogo pionero. Edificio de la Universidad de Costa Rica con la fuente de Cupido y el Cisne al frente en el barrio González Lahmann, al este de la ciudad de San José.
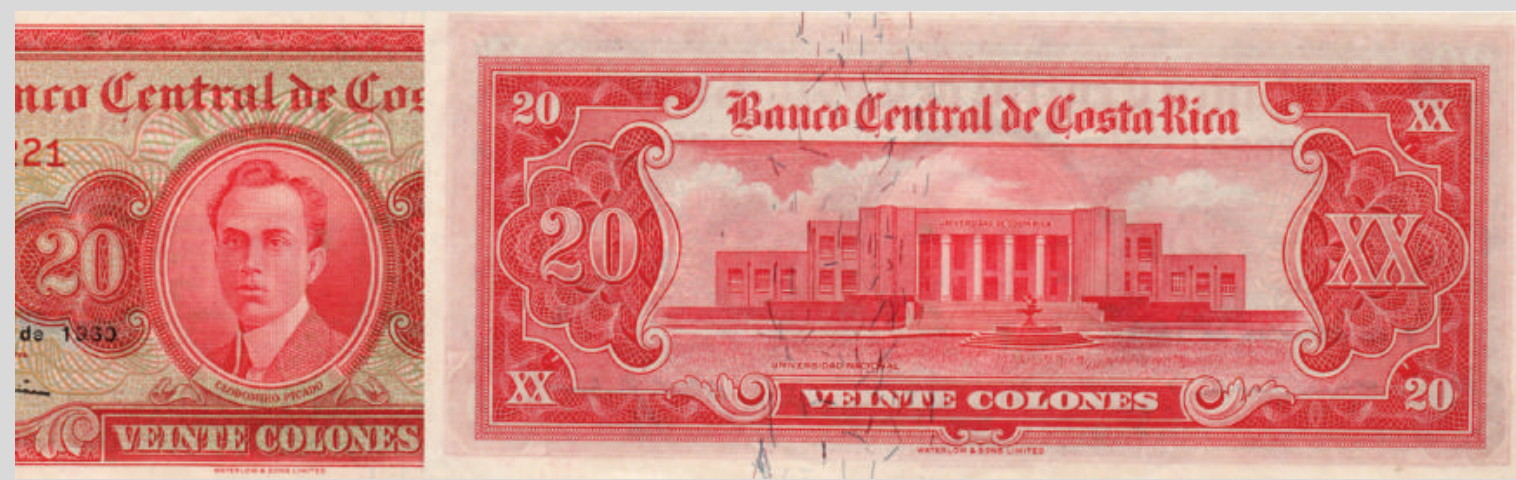

En 1967 hubo una escasez de monedas de dos colones, conocidas como chapas de a dos, por lo que el BCCR puso en circulación un millón de billetes de dos colones utilizando para tal propósito las fórmulas sobrantes del billete de dos colones emitido por el BNCR, e ilustrado anteriormente (Figura No 7). Para poner los billetes en circulación se les imprimió en el anverso con tinta negra, la leyenda Banco Central de Costa Rica, en letras mayúsculas. Los billetes salieron todos con fecha de emisión 5 de diciembre de 1967 (Carranza-Astúa, 2012, p. 364). 
Para muchos de los jóvenes de tal época, entre ellos quien esto escribe, la pregunta de rigor después de indagar un poco de este tema, fue: ¿Dónde está la fuente que aparece en el reverso del billete y que el año siguiente cumpliría un siglo? Pues la fuente se encontraba desarmada en la Universidad de Costa Rica, y no fue hasta 1969 cuando se inició su rescate y restauración, que culminó con su montaje, en enero de 1973, en el patio interno del recién construido edificio de la Facultad de Agronomía (Orozco, 2018). No sabemos si alguna pregunta indiscreta, a causa de la imagen en el billete, atrajo la atención de algunas personas acerca de la fuente desarticulada.

Mi primer encuentro con Cupido y el Cisne fue en ese año de 1973. El patio de la Facultad de Agronomía estaba muy cerca del aula donde recibía mis lecciones de entomología. Recuerdo a la fuente de un color verduzco pálido, tono que la gente llamaba cardenillo, nombre que según el diccionario corresponde a la pátina de los objetos de bronce, aunque la fuente fue fabricada en hierro colado.

Yo había ingresado a la Universidad de Costa Rica en 1968, cuando se empezó a alterar el espacio al oeste del edificio de Estudios Generales, para la construcción de la biblioteca que llevaría el nombre del rector, don Carlos Monge Alfaro. De esa alteración los estudiantes heredamos un pretil como sitio para tertulias, y al frente de la nueva biblioteca, quedó libre un amplio espacio, que años después fue bautizado como Plaza Santo Tomás, en honor a la antigua Universidad de Santo Tomás.

El área al oeste de Estudios Generales, previa a la construcción de la biblioteca, aparece en una tarjeta postal de mediados de la década de 1960. En ella destacan, frente al edificio, un par de árboles. Uno de ellos quedó grabado en el billete de 10 colones emitido por el BCCR entre 1972 y 1987, que incluye el edificio de Estudios Generales y el retrato del rector, don Rodrigo Facio Brenes (Figura No 11), cuyo nombre lleva la Ciudad Universitaria. Detrás del edificio de Generales se aprecia el edificio, inaugurado en 1957, de la Facultad de Educación, que aparece en el reverso de los billetes de 20 colones emitidos por el BCCR entre 1964 y 1970 (Carranza-Astúa, 2012, p. 392). 
Figura $N^{\circ}$ 11. Arriba, anverso del billete de 10 colones del BCCR, 1983, que incluye el edificio de Estudios Generales y el retrato del Rector, Lic. Rodrigo Facio Brenes. Abajo, tarjeta postal de mediados de la década de1960 mostrando el espacio al oeste del edificio de Estudios Generales. Al fondo se aprecia el edificio de la Facultad de Educación (Tarjeta impresa por Fotolitografía Universal y publicada por Carlos Federspiel \& Co., S.A. Librería Universal, San José.

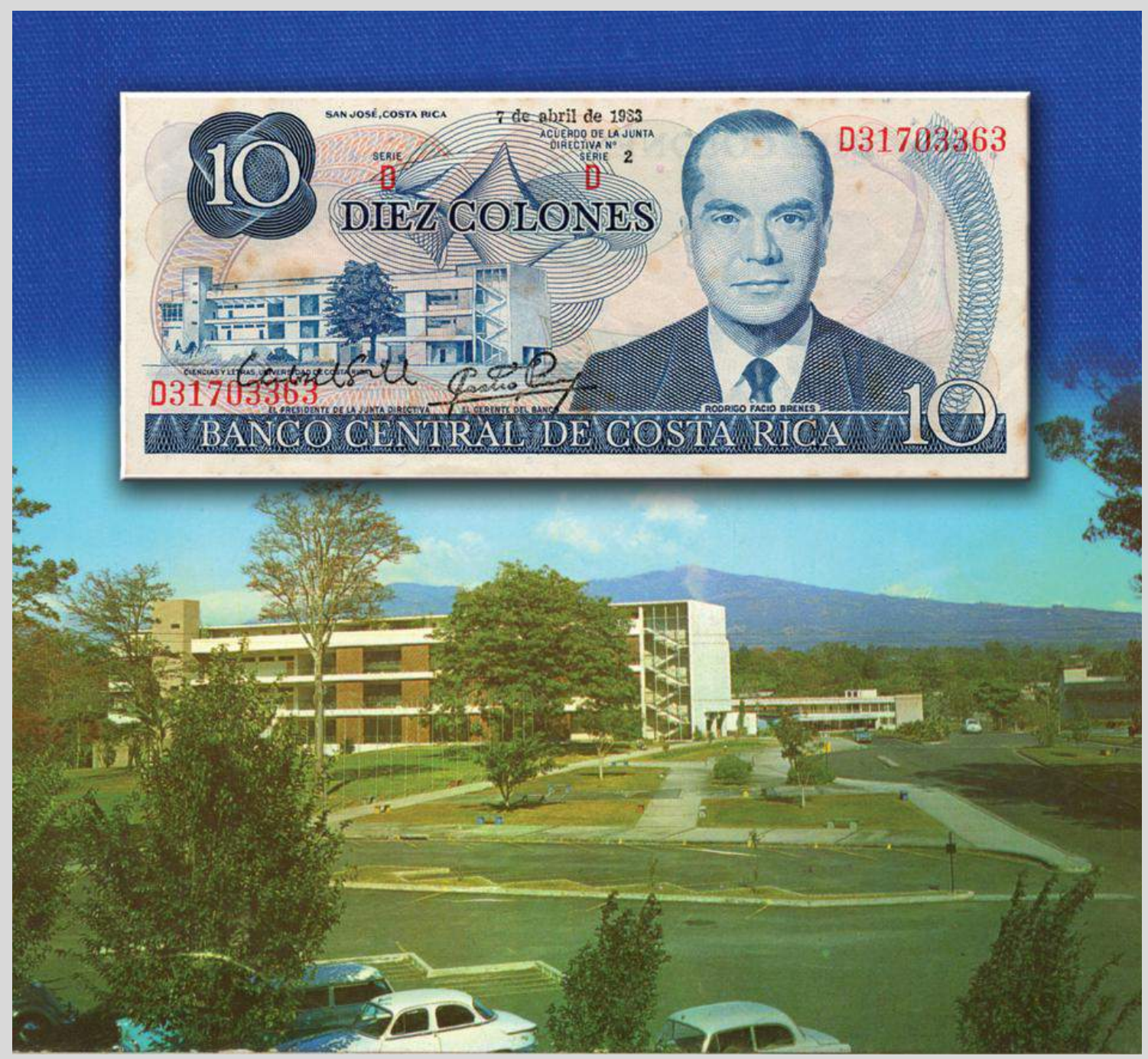

Algunos de los compañeros de estudio nos reuníamos en la cafetería (soda) de Estudios Generales donde una empanada valía una peseta (dos reales, o 25 céntimos) y un café cuatro reales (50 céntimos) o simplemente, un cuatro. Esa jerga monetaria, vigente desde tiempos coloniales, no le hubiese sonado extraña un siglo antes a los estudiantes de la Universidad de Santo Tomás. Tal jerga sobrevivió hasta mediados de la década de 1980, cuando la devaluación del colón hizo obsoletas sus fracciones y los billetes en denominaciones inferiores a 1000 colones, que fueron sustituidos por monedas. 
La fuente de Cupido y el Cisne fue trasladada desde la Facultad de Agronomía hasta la Plaza Santo Tomás, donde fue instalada en 1992 (Orozco, 2016)

\section{La medalla del 75 aniversario de la Universidad de Costa Rica}

La celebración, en el año 2015, del 75 aniversario (1940-2015) de la fundación de la Universidad de Costa Rica, y mi afición por los asuntos numismáticos me llevó, junto con otros colegas universitarios, a proponer la emisión de una medalla conmemorativa de esa importante efeméride. Tal como hemos visto en este recuento histórico, la fuente es la única estructura sobreviviente vecina de la Universidad de Santo Tomás que se integra luego a la Universidad de Costa Rica, por lo que decidimos incluir su grabado en una de las caras de la medalla propuesta. La otra cara llevaría grabado el escudo de la Institución, con el girasol orientado hacia el sol naciente, y el conjunto rodeado por una corona de laurel. La orla de la medalla ostentaría 75 estrellas, una por cada año de funcionamiento de la Institución (Figura № 12).

La iniciativa fue acogida por el rector, Dr. Henning Jensen, y la primera entrega de medallas fue hecha a las 10 horas del 9 de diciembre del 2015, en el auditorio de la Ciudad de la Investigación.

Figura $\mathbf{N}^{\circ}$ 12. Anverso y reverso de la medalla conmemorativa del 75 aniversario (1940-2015) de la fundación de la Universidad de Costa Rica. Metal: plata 999/1000. Peso: $31.1 \mathrm{~g}$. Diámetro: 40 $\mathrm{mm}$. Espesor: $3 \mathrm{~mm}$. Emisión: 520 piezas. Acuñación: Casa de Moneda de México. Diseñador: Prof. José Maria Castro Madriz, UCR. Primera emisión: 2015. Plan de entrega: cuatro medallas anuales hasta el centenario de la Universidad de Costa Rica en el 2040.

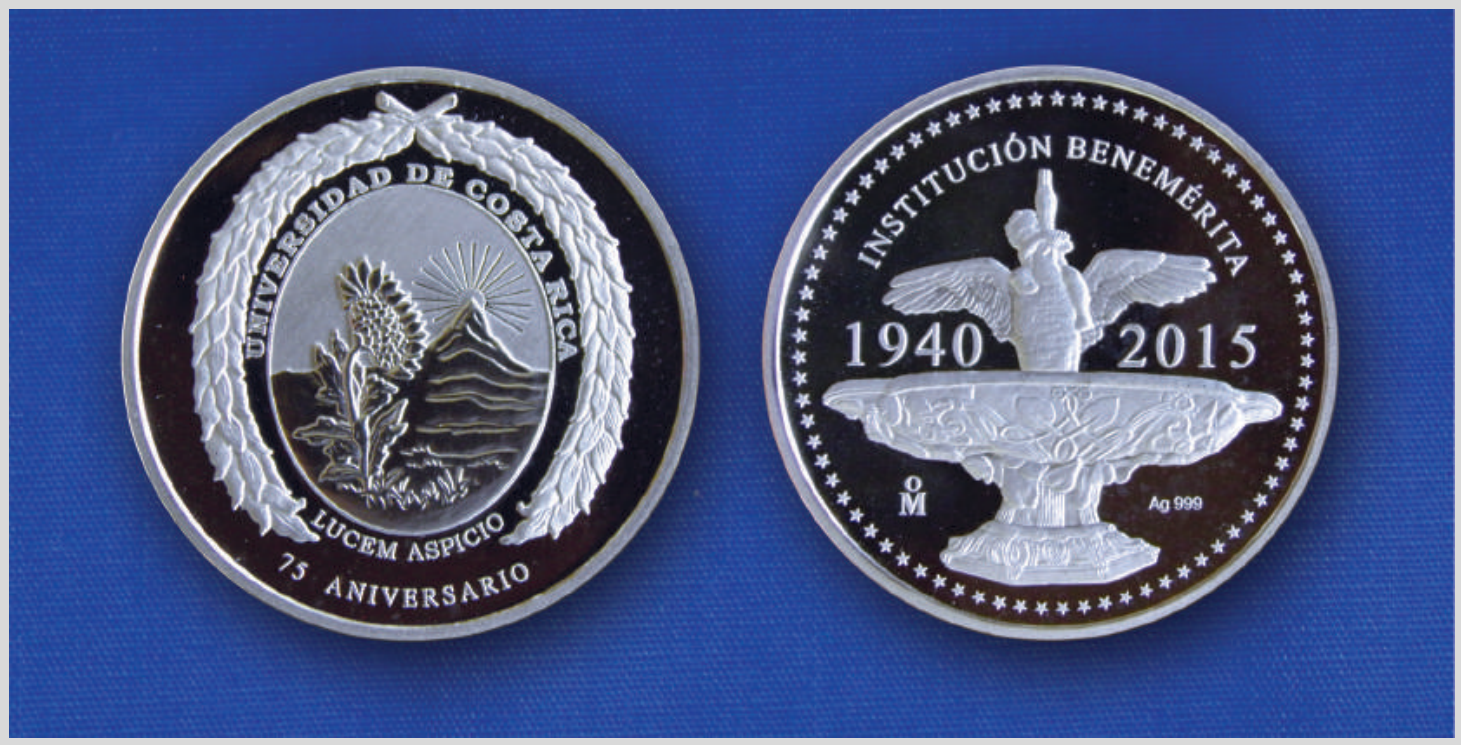


Decimos la primera entrega, porque en la propuesta original sugerimos que cuatro ejemplares de la medalla fueran otorgadas, cada año, a personajes destacados de la Institución, en la docencia, la investigación, la acción social, y al o la mejor estudiante, respectivamente. La última entrega se haría para conmemorar el centenario de la Institución en el 2040.

Una parte (300 piezas) de la emisión total fue destinada para ser adquirida por funcionarios y estudiantes de la Universidad, una pieza por persona, a precio de costo (45.000 colones, equivalentes a 90 dólares). Cada medalla, protegida por un acrílico que preserva el brillo del metal, tiene numerada su caja, así como el certificado de autenticidad que informa sobre las calidades de la pieza y otros datos.

Como hecho curioso, el fundador de la Universidad de Santo Tomás fue el Dr. Castro Madriz. Uno de sus descendientes actuales, que lleva el mismo nombre y apellidos, y profesor de la Universidad, fue el encargado del diseño de la medalla. La acuñación en plata pura (999 milésimas) fue hecha por la Casa de Moneda de México, la primera casa de moneda (ceca) fundada en Tierra Firme, y en actividad continua desde 1543.

\section{Algunos datos sobre Cupido y el Cisne}

Los dos traslados de la fuente a los espacios de la Universidad de Costa Rica respetaron las formas y proporciones originales del complejo instalado en 1868. La fuente de Cupido y el Cisne, tal como se observa hoy en la plaza Santo Tomás (Figura $N^{\circ}$ 13) consta de cinco elementos principales: 1. La base formada por tres octágonos de concreto escalonados. 2. La pila circular de concreto, recubierta por una fachada de hierro que cubre, desde la base hasta la parte superior del borde. La fachada tiene ocho soportes equidistantes adornados con volutas, que ocultan las uniones de las secciones desmontables. 3 . Una columna de concreto dentro de la pila. 4. Un pedestal metálico sobre la columna sostiene una copa metálica en forma de flor de cuatro pétalos. El pedestal y la copa están ornamentados con hojas similares a las del nenúfar europeo 
(Nymphaea alba), planta acuática, de pecíolos largos, hojas flotantes y flores blancas globulares, común en estanques de jardines. 5. La escultura, con Cupido montado sobre el cuello de un cisne con las alas desplegadas y el cuello erguido. Cupido no lleva arco ni flechas, luce alas pequeñas en su espalda y sostiene con su mano derecha un par de brotes de flor de nenúfar.

La altura del complejo, desde la base de la primera grada octagonal al pico del cisne es de $4.0 \mathrm{~m}$. La altura, desde la base del pedestal metálico interno y hasta el extremo del pico de cisne es de $2.7 \mathrm{~m}$. El diámetro de la pila en la mitad de su borde superior es de $4.8 \mathrm{~m}$, y la altura del borde desde la base es de $0.6 \mathrm{~m}$. La copa tiene un diámetro de $2.1 \mathrm{~m}$. La envergadura del cisne es de $2.0 \mathrm{~m}$.

La fabricación de la fuente, en secciones desmontables, facilitó su embalaje y transporte desde Inglaterra hasta la capital y, luego, sus traslados a las dos sedes de la Universidad de Costa Rica.

Cabe preguntarse ¿por qué se le construyó a la fuente una base octogonal desde un principio? Según Tresidder (2004, p.349), desde la antigüedad el octágono es un símbolo de resurgimiento a la vida eterna y se supone sirve de mediador entre los simbolismos atribuidos al cuadrado (existencia terrenal) y al círculo (existencia celestial). Recordemos que la plaza Principal tenía forma de cuadrado y la pila de la fuente es circular. Podemos especular que en 1868 con esas figuras geométricas se quiso representar el recorrido del agua, desde la tierra donde surge el manantial, hasta ser lanzada al cielo por el chorro que emana del pico del cisne y es recibida limpia en la pila. Lo dejamos a su criterio estimado lector.

En este contexto, los ocho soportes del borde de la pila tal vez representaban los puntos cardinales e inter-cardinales (Ver coordenadas de la ciudad de San José en la Figura № 2, y la orientación de Cupido y el Cisne en la Figura № 6). En una fotografía de 1912 reproducida por $\operatorname{Orozco}$ (2016, p. 100), Cupido y el Cisne están orientados, como corresponde por respeto, de cara hacia la bandera de Costa Rica que ondeaba en el Cuartel Principal, situado en la cuadra al norte del Parque Central. 
Figura $N^{\circ}$ 13. La fuente de Cupido y el Cisne en octubre del 2018. Plaza Santo Tomás. Ciudad Universitaria Rodrigo Facio. Al fondo, la biblioteca Carlos Monge Alfaro. Foto Nuria Gutiérrez, Archivo Universitario Rafael Obregón Loría (AUROL).

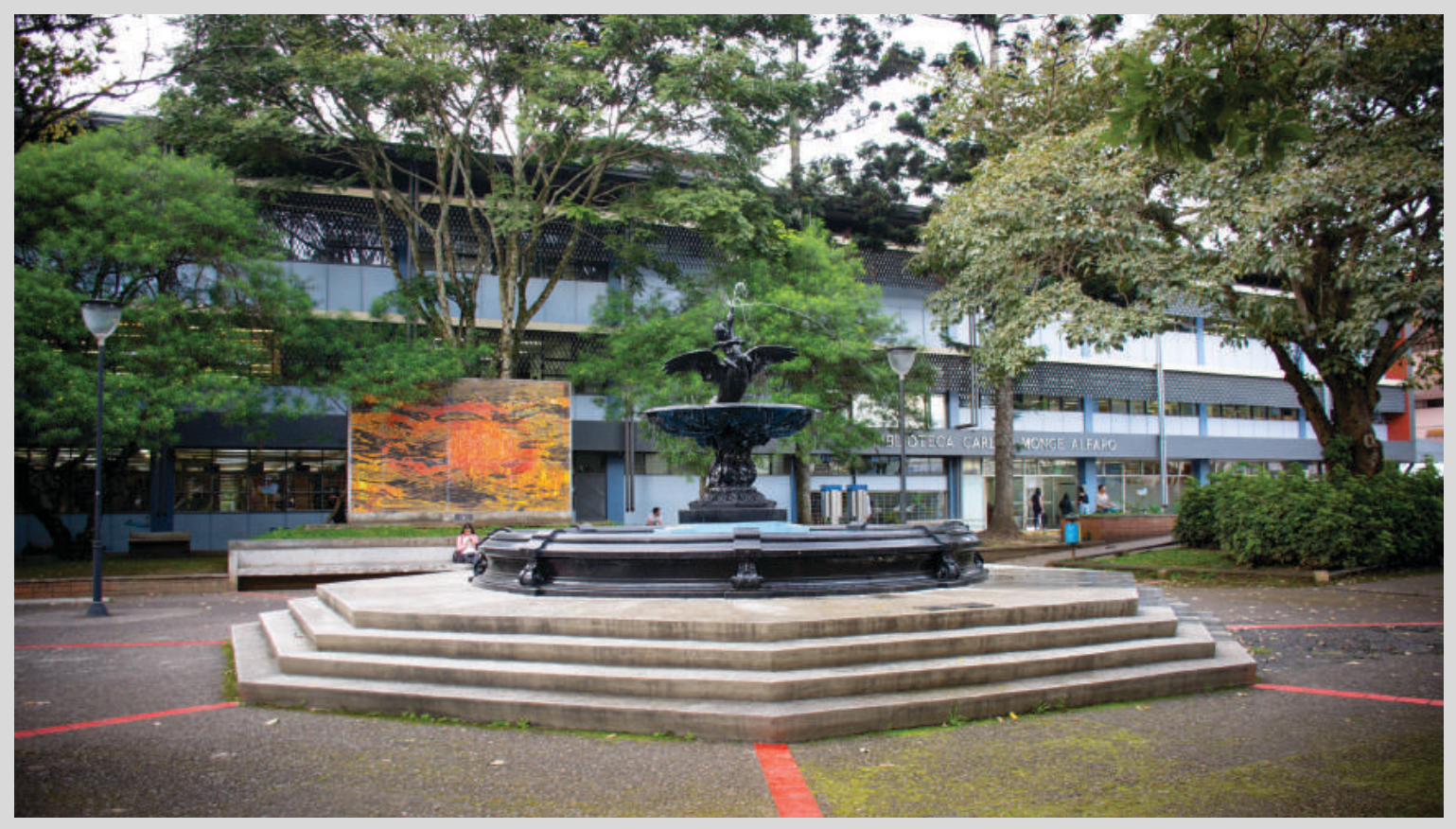




\section{BIBLIOGRAFÍA}

Araya, C. (1973). La minería y sus relaciones con la acumulación de capital y la clase dirigente de Costa Rica, 1821-1841. Anuario de Estudios Sociales Centroamericanos, 2 (5): 31-64.

Carranza, J. A. (2012). Historia de los billetes de Costa Rica, 1858-2012. San José. J. Carranza. 497 p.

Fernández, L. (1889). Historia de Costa Rica durante la dominación española 1509-1821. Publícala Ricardo Fernández Guardia. Madrid. España. Tipografía de Manuel Ginés Hernández. 671 p.

Fernández, R. (2002). Costa Rica en el siglo XIX. Antología de Viajeros. San José. Editorial de la Universidad Estatal a Distancia. 495 p.

González, P. (1989). La Universidad de Santo Tomás. San José. Editorial de la Universidad de Costa Rica. 182 p.

González, M. (1998). Cuentos de Magón. San José. Editorial Costa Rica. 408 p.

Hilje, L. (2007). Karl Hoffmann: Cirujano Mayor del Ejército Expedicionario. Alajuela. Colegio Universitario de Alajuela. 276 p.

Hilje, L. (2013). Trópico agreste: La huella de los naturalistas alemanes en la Costa Rica del siglo XIX. Cartago. Editorial del Instituto Tecnológico de Costa Rica. 865 p.

León, J. (2002). Evolución del comercio exterior y del transporte marítimo de Costa Rica, 1821-1900. Colección Historia de Costa Rica, Vol. 7. San José. Editorial de la Universidad de Costa Rica. 384 p.

Meagher, T. F. (1860). Holidays in Costa Rica. Harper's New Monthly Magazine, 20 (116): 18-38, 145-164, 304-325.

Molina, C. (2005). Y las mulas no durmieron... los arrieros en Costa Rica. Siglos XVI al XIX. San José. Editorial de la Universidad Estatal a Distancia. 560 p. 
Murillo, J. (2004). Historia de las Monedas de Costa Rica. Catálogo Numismático. San José. Editorial de la Universidad Estatal a Distancia. 256 p.

Orozco, S. (2016). Delfines, leones y tritones. Fuentes victorianas de hierro en las plazas y parques de Costa Rica (1868-1880). Revista Herencia, 29, (1): 95 - 140.

Picado, M. (1964). Vida y obra del doctor Clodomiro Picado. San José. Editorial Costa Rica. 286 p.

Tresidder, J. (2004). The Complete Dictionary of Symbols. San Francisco. Estados Unidos de América. Chronicle Books. 544 p.

Vargas, J. A. \& Gómez, J. (2006). Palmeras, palmas y mirtos en monedas de Costa Rica (1825-1951). Lankesteriana, 6 (2): 65 - 71.

Vargas, J. A. (2012). Rescatemos una herencia: notafilia costarricense. Revista Herencia, 26 (1-2): 7-24.

Vargas, J. A. (2014). Una encina (Quercus sp.) en monedas y billetes de Costa Rica (1848-1948). Revista Reflexiones, 93 (2): 35 - 53.

Vega, P. (1991). De la banca al sofá: La diversificación de los patrones de consumo en San José (1857-1861). Revista de Historia, 24: 56-87. 